\title{
Vincent du Vigneaud: following the sulfur trail to the discovery of the hormones of the posterior pituitary gland at Cornell Medical College
}

\author{
Malte Ottenhausen, MD, Imithri Bodhinayake, MD, ${ }^{1}$ Matei A. Banu, MD, ${ }^{1}$ Philip E. Stieg, PhD, MD, ${ }^{1}$ \\ and Theodore H. Schwartz, MD ${ }^{1-3}$

\begin{abstract}
1Department of Neurosurgery, Sackler Brain and Spine Center; ${ }^{2}$ Department of Otolaryngology; and ${ }^{3}$ Department of Neuroscience, Brain and Mind Institute, Weill Medical College of Cornell University, NewYork-Presbyterian Hospital, New York, New York

In 1955, Vincent du Vigneaud (1901-1978), the chairman of the Department of Biochemistry at Cornell University Medical College, was awarded the Nobel Prize for Chemistry for his research on insulin and for the first synthesis of the posterior pituitary hormones-oxytocin and vasopressin. His tremendous contribution to organic chemistry, which began as an interest in sulfur-containing compounds, paved the way for a better understanding of the pituitary gland and for the development of diagnostic and therapeutic tools for diseases of the pituitary. His seminal research continues to impact neurologists, endocrinologists, and neurosurgeons, and enables them to treat patients who had no alternatives prior to du Vigneaud's breakthroughs in peptide structure and synthesis. The ability of neurosurgeons to aggressively operate on parasellar pathology was directly impacted and related to the ability to replace these hormones after surgery. The authors review the life and career of Vincent du Vigneaud, his groundbreaking discoveries, and his legacy of the
\end{abstract} \\ understanding and treatment of the pituitary gland in health and disease.
}

http://thejns.org/doi/abs/10.3171/2015.5.JNS141952

KEY WORDS history; pituitary; Nobel Prize; Vincent du Vigneaud; chemistry; oxytocin; vasopressin

$\mathrm{G}$ ROUNDBREAKING scientific discoveries have paved the way for progress in neurosurgery. Radical pituitary and parasellar surgeries were only possible once we possessed the ability to replace pituitary hormones. This is the legacy of Vincent du Vigneaud, a brilliant scientist whose interest in the biochemistry of sulfur-containing compounds led to the synthesis of the first polypeptide hormones: oxytocin and vasopressin. For his work and contribution to medicine, Vincent du Vigneaud was awarded the Nobel Prize in 1955. Spanning the tumultuous years of the 20th century, du Vigneaud's sulfur trail and his journey to fame are the embodiment of resilience and a passion for science.

\section{Early Life and Career}

Vincent du Vigneaud's career in polypeptide hormones has its roots in his early childhood experiences and educa- tion in Illinois. As the son of a machine designer, Alfred du Vigneaud, his interest in science and technology along with his inquisitive nature became evident early on. Born in the midst of the Progressive Era on May 18, 1901, in Chicago, Illinois, Vincent du Vigneaud exercised his interest in chemistry from his adolescent years. In a time of turmoil and war, science and, in particular, chemistry, proved to be not just a necessity but also a true calling for young du Vigneaud. While modernization and scientific development were mainly driven by industrialization and the Efficiency Movement at the time, the US was truly established as a global player after its involvement in World War I. Furthermore, it was the war and the use of chemical weapons that induced a significant boost in chemistry research worldwide, setting the stage for numerous inventions and discoveries in the field. Not only great mentors and talent but also the historical context paved the way for du Vigneaud's brilliant discoveries. 
Well before graduating from Carl Schulz high school in 1918, or taking any chemistry course, du Vigneaud and his friends were experimenting in a friend's basement with chemicals (including sulfur-based ones) obtained from a neighborhood pharmacist. ${ }^{1}$ As a high school senior during World War I, when young boys were encouraged to participate in work programs prior to graduation, he worked on a farm near Caledonia, Illinois. His savings from his work on the farm, along with contributions and encouragement from his sister, helped him decide on pursuing higher education as an undergraduate in chemical engineering at the University of Illinois at Urbana-Champaign. Du Vigneaud's family was well educated but lacked financial resources. He therefore had to work his way through college, performing jobs of all kinds, such as apple picking and tearing down boilers. ${ }^{6}$ His modest beginnings left deep marks. Colleagues at Cornell remember him as extremely determined and hardworking, always aware of his goals and the means available to achieve them. The sulfur trail was not a red carpet.

At the University of Illinois, he encountered two lifelong constants; his interest in the chemistry of biological compounds and his future wife, Zella Zon Ford. During his first year (1920), he found that he was more interested in chemistry than in engineering, particularly the organic chemistry of medicinal substances, ${ }^{8}$ and he switched his major to chemistry. At the University, he met Professors C. S. Marvel, H. B. Lewis, and W. C. Rose, who would become significant influences during the course of his career. It was professor Marvel who first piqued his interest in the relationship of structure to biological activity and served as the mentor for both his senior and master's theses. Professor Lewis exposed him to what du Vigneaud termed "the trail of his research"; sulfur-containing compounds. The inspiration to focus on the first major sulfurcontaining compound on this trail came from Professor Rose's 1923 lecture on insulin.

After completing his master's degree at the University of Illinois in February 1924, he accepted a position in the analytical laboratory of DuPont in Wilmington, Delaware. In the summer of 1924 he married Zella, but their time in Wilmington was brief. By the fall of 1924, at the recommendation of Professor Marvel, du Vigneaud accepted an assistant biochemist research position at the Philadelphia General Hospital that exposed him to clinical chemistry and gave him the opportunity to teach at the Graduate School of Medicine, University of Pennsylvania. Professor Marvel continued to guide du Vigneaud along the sulfur trail. Du Vigneaud could not afford the trip to Philadelphia; Professor Marvel offered to pay for the trip in exchange for du Vigneaud's preparation of 10 pounds of cupferron for the laboratory.

His mentors from the University of Illinois, Professors Marvel, Lewis, and Rose, soon helped him work toward a doctoral degree by recommending him as a graduate student to Professor Murlin at the University of Rochester School of Medicine, New York. Professor Murlin was a physiologist isolating and studying insulin. Vincent du Vigneaud's chemistry background was integral to Professor Murlin's investigations. At that time, there was growing suspicion that insulin contained sulfur. Using insulin extracts initially isolated from pancreatic tissue obtained from slaughterhouses and later obtained from Eli Lilly and Company, he pursued the identity of the sulfur moiety in insulin. As du Vigneaud later recounted in an interview with R. A. Plane, ${ }^{8}$ by investigating changes in the lability of insulin after hydrolysis, he showed that the sulfur moiety was a cysteine derivative present as a disulphide linkage. His thesis work, "The Sulfur of Insulin," was published in November 1927 in the Journal of Biological Chemistry.

These findings on the cysteine moieties were consistent with the behavior predicted by the crystalline structure of insulin published in the previous year by Professor J. J. Abel at the Department of Pharmacology at The Johns Hopkins University Medical School. Upon completion of his PhD work, du Vigneaud was able to join Dr. Abel's laboratory at Johns Hopkins through a National Research Council Fellowship. Dr. Abel had already started focusing his research on posterior pituitary hormones. Together they crystallized insulin on a larger scale, isolated crystallized cysteine from crystallized insulin and, in collaboration with Drs. O. Wintersteiner and H. Jensen, elucidated the chemistry of insulin, helping to establish it as a protein.

Vincent du Vigneaud then extended his fellowship to spend a second year (1929) abroad with Max Bergemann at the Kaiser Wilhelm Institute in Dresden, Germany, to work on the synthesis of peptides. From Germany he went to Scotland to work for a few months with Georg Barger at The University of Edinburgh Medical School, and then to England to work with Sir Charles R. Harrington at the University College Hospital Medical School in London. While the US was struggling through the "dirty thirties," with dust storms and the Great Depression, the boy who once wanted to become a farmer became a cosmopolitan and internationally known researcher, establishing vital connections with world-renowned scientists.

By the end of this postdoctoral fellowship, du Vigneaud had several job offers back in the US from his previous mentors at the University of Illinois, the University of Rochester, Johns Hopkins, and the University of Pennsylvania. He had already decided that he wanted to pursue biochemistry and conduct research in an environment that mentored graduate students. He therefore accepted the offer from the University of Illinois to work with Professor Rose in the Department of Physiological Chemistry. There, he continued working on the chemistry of insulin and branched out to investigate amino acids. It was during this period that he discovered that dietary cysteine could be replaced by homocysteine.

The early career of Vincent du Vigneaud (Fig. 1) was shaped by both continuity and diversity; continuity as portended by his ongoing research of sulfur-based compounds, and diversity as evidenced by his many different collaborations and work environments. As he later claimed, he had "the privilege and the thrill of following those researchers that [he] wanted to do." 8 Just 3 years after moving to the University of Illinois, du Vigneaud was offered a professorship position in biochemistry in Washington, DC, at the George Washington University School of Medicine. By the time he moved to Washington, DC, in 1932, he was no longer just a fellow exploring his interest in the biochemistry of sulfur-containing compounds, but 


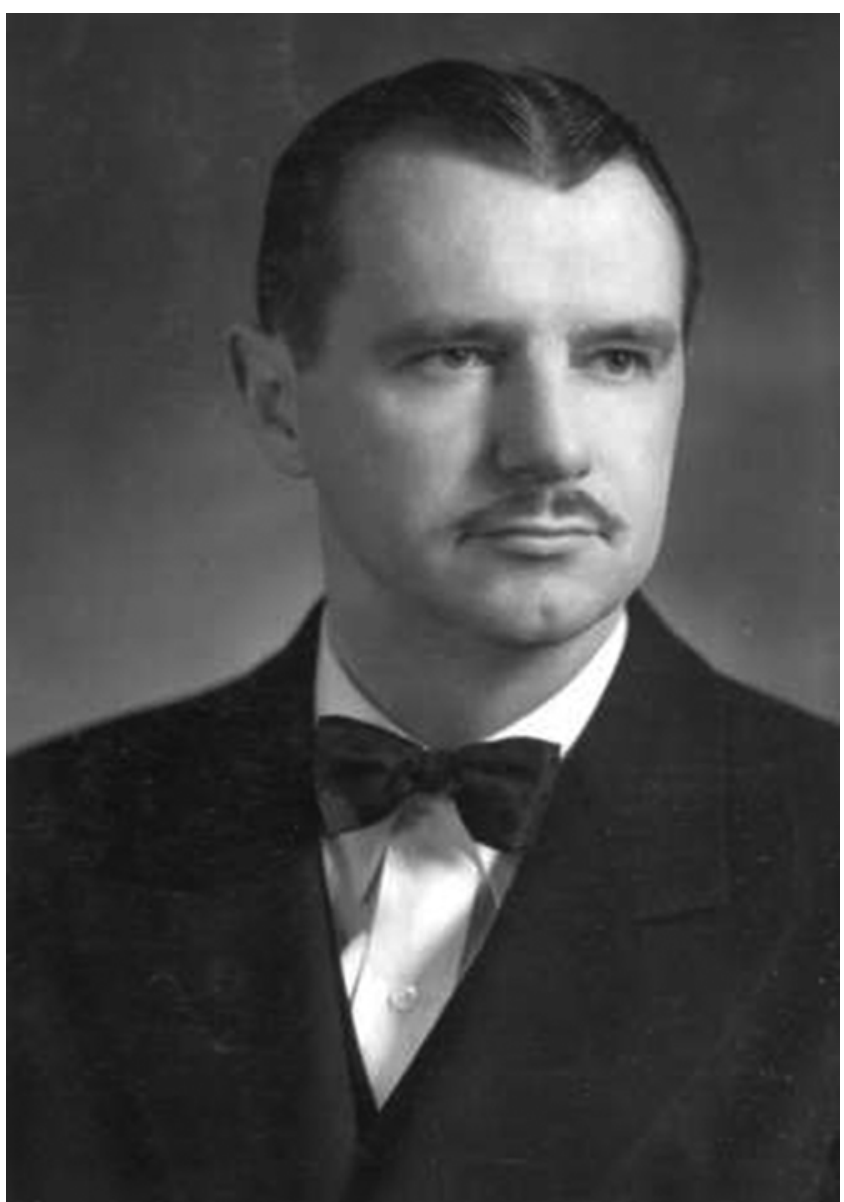

FIG. 1. Undated picture of Vincent du Vigneaud. Copyright Theodore H. Schwartz. Courtesy of the Medical Center Archives of NewYorkPresbyterian/Weill Cornell.

a world-renowned expert in the field of organic chemistry and physiology.

Three of his former graduate students and a postdoctoral fellow who had just finished his PhD at the University of Illinois moved with him to Washington, DC. His exceptional teaching and mentoring capabilities as well as his rigorousness in maintaining continuity once again came into play. These were key points throughout du Vigneaud's entire career. Transplanting successful elements from his previous positions into new environments allowed him to adapt rapidly and to continue his work quickly and efficiently irrespective of environment. At George Washington, du Vigneaud started investigating the sulfur-containing hormones of the posterior pituitary, an interest that stemmed from his interest in the sulfur moieties of insulin. It was here that his research was first acknowledged by his peers, with an award from the Chemical Society of Washington in 1937 for his work on "The chemistry of biologically significant sulfur compounds, and especially for the synthesis of glutathione." ${ }^{8}$ However, throughout his entire life, including in the moments following his Nobel Prize win, du Vigneaud expressed his skepticism and distrust regarding academic prizes. The true rewards and real recognition of his work would stem not from scientific committees but rather from the patients directly benefiting from his work.

\section{New York and the Synthesis of Oxytocin and Vasopressin}

After 6 very successful and productive years at George Washington University, he moved to New York City in 1938 to become the Chairman of the Department of Biochemistry at Cornell Medical College (Fig. 2). Yet again, his research team at Cornell had continuity with his team at George Washington, with 5 of his former research group members joining him in New York. At Cornell he continued to develop and refine his research on insulin and the posterior pituitary hormones. Additionally, he added a significant body of knowledge to biochemistry. He established the structure of vitamin $\mathrm{H}$ (biotin), determined the mechanism of transsulfuration of methionine to cysteine, and determined the mechanism of transmethylation of choline and homocysteine to methionine. His group even worked on the chemistry of penicillin during World War II (1939-1945). Du Vigneaud suffered greatly as his former colleagues endured terrible circumstances in Europe. However, during the war and throughout the entire period of the Cold War there was a massive surge of capital into scientific research, specifically in chemistry and medicine. Once again, the historical context played an important part in du Vigneaud's scientific path.

After the war, he continued to work on one of the posterior pituitary hormones, oxytocin. After initially isolating and purifying it, he drew on methods he had developed at George Washington University for glutathione synthesis to synthesize oxytocin in 1953. These methods included the initial protection of the sulfur groups using benzyl groups, and subsequent removal of the benzyl groups using sodium and liquid ammonia. ${ }^{8}$ This work marked the first synthesis of a polypeptide hormone. The enormous importance of his research contributions was recognized by several awards during his time at Cornell, such as the Mead Johnson Award and the Osborne and Mendel Award in $1943,{ }^{1}$ the Nichols Medal in 1945, the Lasker Award from the American Public Health Association in 1948, the Nobel Prize in 1955, and the Gibbs Medal in 1956.

The Nobel Prize recognized his "work on biochemically important sulfur-containing compounds," especially "the first synthesis of a polypeptide hormone." In his Nobel lecture on December 12, 1955, du Vigneaud acknowledged the trail of sulfur research that spanned his career, saying that the synthesis of the sulfur-containing oxytocin "was the culmination of many experiences along a trail of research stemming from my original interest in sulfur and in insulin." 5 This connection is detailed further in his book, A Trail of Research in Sulfur Chemistry and Metabolism, and Related Fields, ${ }^{4}$ which sums up his scientific work prior to receiving the Nobel Prize.

\section{Nobel Prize and Legacy}

The impact of Vincent du Vigneaud's research extends well beyond the realm of organic chemistry. The recognition by the Nobel Committee for Chemistry of the 


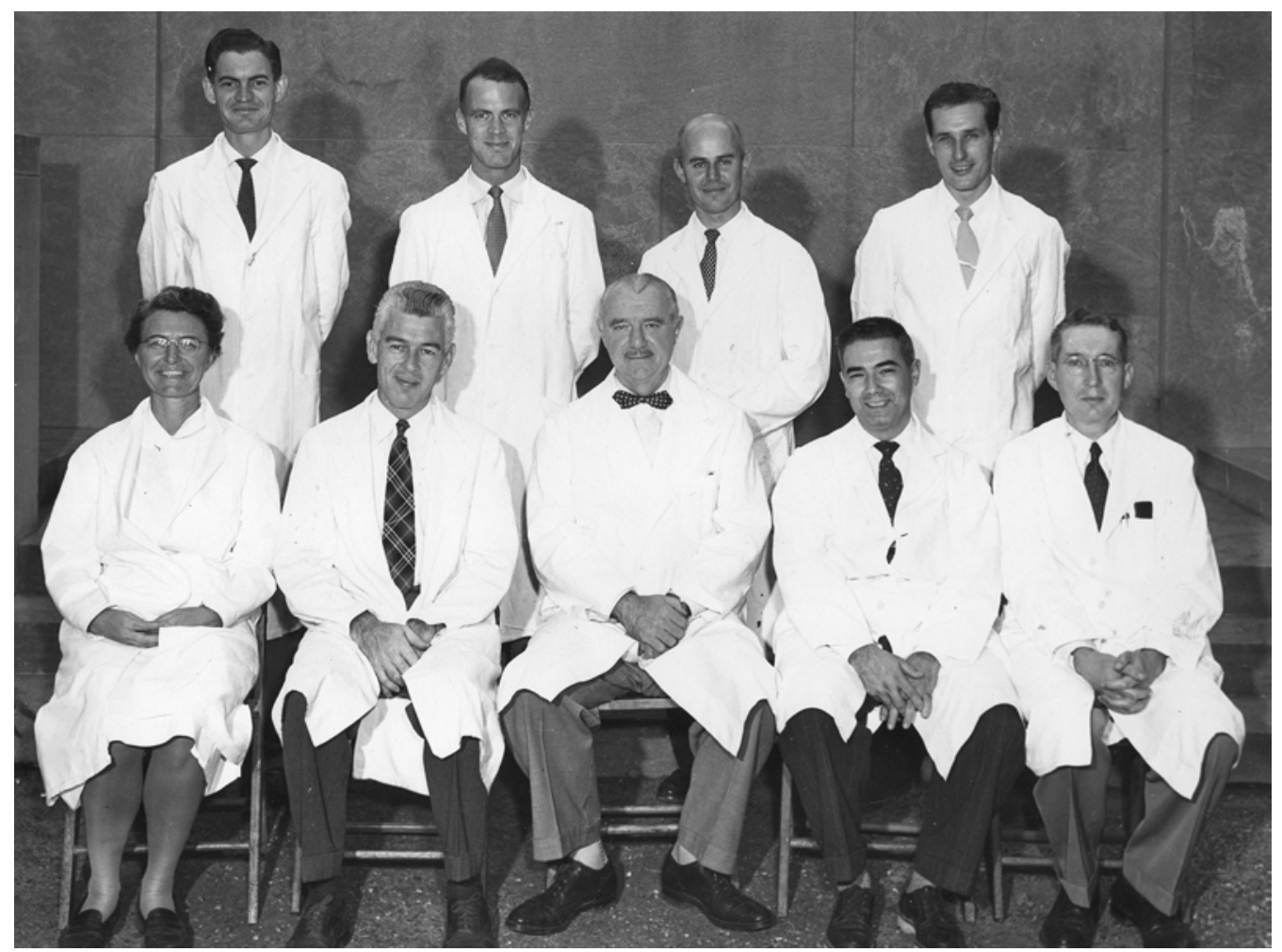

FIG. 2. Department of Biochemistry at Cornell University, 1952-1954. Standing, left to right: Charles Otken, Roger Roeske, Peter Condliffe, Darrell Ward. Seated, left to right: Dorothy Genghok, Donald Melville, Vincent du Vigneaud, Julian Rachele, Roy Bonsnes. Copyright Theodore H. Schwartz. Courtesy of the Medical Center Archives of NewYork-Presbyterian/Weill Cornell.

Royal Swedish Academy of Sciences was a culmination of multiple nominations. Before receiving the Nobel Prize in Chemistry in 1955 (Fig. 3), he was nominated several times in physiology, medicine, and organic chemistry. He received multiple nominations for the Nobel Prize in Chemistry almost every year between 1944 and 1955, and for the Nobel Prize in Physiology or Medicine from 1943 on. The synthesis of oxytocin and vasopressin in 1954 is considered the breakthrough that finally led to the Nobel Prize in $1955 .{ }^{9}$

He went beyond the synthesis of these hormones and was involved in the first clinical trials and translational applications, such as the use of oxytocin to stimulate milk ejection ${ }^{7}$ or the use of vasopressin as a hemostatic in surgery. ${ }^{3}$ His research efforts both expanded the available medical treatment options for posterior pituitary disease and paved the way for clinical trials using hormone therapy. Oxytocin is now widely used for the induction of labor and the prevention of postpartum hemorrhage, ${ }^{2}$ and vasopressin analogs such as desmopressin are used in the treatment of diabetes insipidus. Indeed, the ability to administer desmopressin has allowed neurosurgeons to remove and cure tumors of the parasellar area, such as adenomas and craniopharyngiomas, that require chemical supplementation of these hormones for patient survival. One might argue that modern pituitary and parasellar surgery has been made possible through du Vigneaud's groundbreaking work, work that paved the way for hormone replacement therapy of all kinds.

Vincent du Vigneaud's landmark work in synthesizing the posterior pituitary hormones was instrumental in the establishment of their biological effects. As he himself predicted during his Nobel lecture:

The establishment of the structure of oxytocin and vasopressin will undoubtedly open the door to a better understanding of these hormones by the biochemist, the physiologist, the pharmacologist and the clinician. Moreover, it should provide suitable basis for the study of the relationship of chemical structure to biological activity in these protein-like substances. The synthesis of oxytocin will afford a means of obtaining the compounds necessary to the study of this relationship and may, in addition, point the way to the synthesis of more complex sulfur-containing polypeptides. ${ }^{5}$

After receiving the Nobel Prize, he received honorary degrees from the University of Illinois, the University of Rochester, and Yale University. He was also a member of the National Academy of Sciences. After achieving emeritus status at Cornell University Medical College in 1967, $\mathrm{du}$ Vigneaud moved to Cornell University in Ithaca to continue research in the Department of Chemistry on oxytocin, vasopressin, and their analogs. As he so frequently declared, academic awards were not a driving force for his work. He therefore continued to search for answers with the same tenacity and determination after his Nobel Prize. He focused his efforts entirely on research until he suffered a massive stroke in 1974. He died on December 11, 1978, in White Plains, New York. In 2001, Antigua and Barbuda issued a stamp with his portrait in honor of his contributions. $^{10}$ 


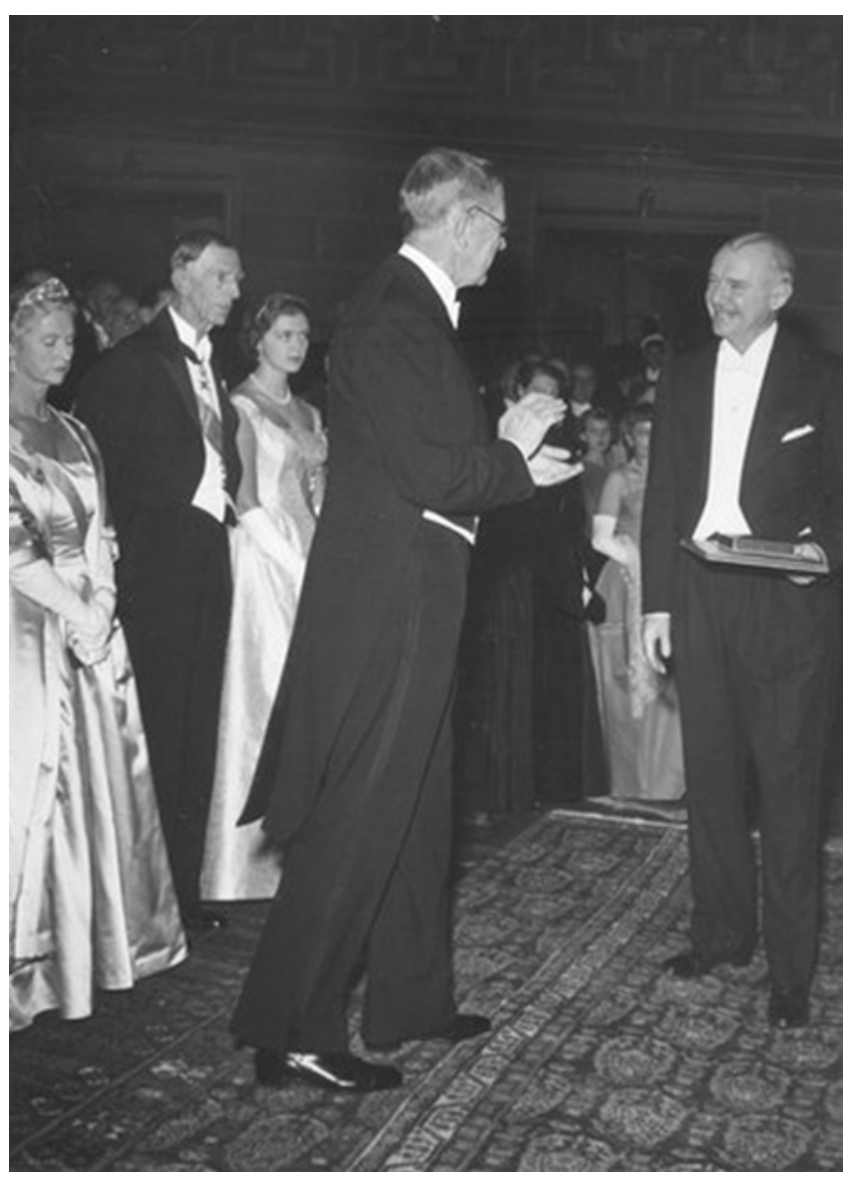

FIG. 3. Vincent du Vigneaud receives the Nobel Prize, Stockholm, December 10, 1955. Copyright Theodore H. Schwartz. Courtesy of the Medical Center Archives of NewYork-Presbyterian/Weill Cornell.

\section{Conclusions}

Vincent du Vigneaud's synthesis of the first polypeptide hormone marked a milestone in both organic chemistry and in medicine. The synthesis of oxytocin and vasopressin in particular permitted the use of these hormones in clinical practice. This had a profound impact on patient care, particularly during childbirth, and in the management of parasellar tumors such as adenomas and craniopharyngiomas. Radical pituitary surgery has been made possible by du Vigneaud's work. Vincent du Vigneaud's lifelong dedication to the biochemistry of sulfur-containing compounds was the focus that led him on a path to discovery that had far-reaching and long-lasting impact throughout multiple fields of medicine. It is therefore important to remember that the findings of pioneers in other fields of science have advanced and shaped our field into what it is today.

\section{Acknowledgment}

We are grateful for the help of the employees of the Archive at Weill Cornell Medical College.

\section{References}

1. Bing FC: Vincent du Vigneaud (1901-1978): a biographical sketch. J Nutr 112:1463-1473, 1982

2. den Hertog CE, de Groot AN, van Dongen PW: History and use of oxytocics. Eur J Obstet Gynecol Reprod Biol 94:8-12, 2001

3. Dillon TF, Marbury BE, Bonsnes RW, Douglas RG, Du Vigneaud V: Vasopressin as a hemostatic in gynecologic surgery; a preliminary report. Obstet Gynecol 11:363-371, 1958

4. du Vigneaud V: A Trail of Research in Sulfur Chemistry and Metabolism, and Related Fields. Ithaca, NY: Cornell University Press, 1952

5. du Vigneaud V: Trail of sulfur research: from insulin to oxytocin. Science 123:967-974, 1956

6. Hofmann K: Vincent du Vigneaud 1901-1978. Washington, DC: National Academy of Sciences, 1987

7. Nickerson K, Bonsness RW, Douglas RG, Condliffe P, Du Vigneaud V: Oxytocin and milk ejection. Am J Obstet Gynecol 67:1028-1034, 1954

8. Plane RA: Interview with Vincent du Vigneaud. J Chem Educ 53:8-12, 1973

9. Ragnarsson U: The Nobel trail of Vincent du Vigneaud. J Pept Sci 13:431-433, 2007

10. Shampo MA, Kyle RA, Steensma DP: Vincent du Vigneaud-Nobel Prize in chemistry. Mayo Clin Proc 88:e99, 2013

\section{Disclosure}

Dr. Schwartz owns stock in Visionsense, is a consultant for Karl Storz, and receives support of a non-study-related clinical or research effort from the NIH.

\section{Author Contributions}

Conception and design: all authors. Acquisition of data: Bodhinayake. Drafting the article: Schwartz, Ottenhausen, Bodhinayake, Banu. Critically revising the article: Schwartz, Ottenhausen, Banu, Stieg. Reviewed submitted version of manuscript: Schwartz, Ottenhausen, Stieg. Approved the final version of the manuscript on behalf of all authors: Schwartz.

\section{Correspondence}

Theodore H. Schwartz, Department of Neurosurgery, Weill Cornell Medical Center, NewYork-Presbyterian Hospital, 525 E. 68th St., Box 99, New York, NY 10021. email: schwarh@med. cornell.edu. 